Journal of Engineering and Applied Sciences 6 (1): 21-26, 2011

ISSN: 1816-949X

(C) Medwell Journals, 2011

\title{
Mechanical and Magnetic Properties of Electrodeposited CoMnP Thin Film Alloys
}

\author{
${ }^{1}$ M.RM. Krishnappa, ${ }^{2}$ N. Rajasekaran, ${ }^{3}$ S. Ganesan and ${ }^{4}$ R.N. Emerson \\ ${ }^{1}$ Department of Physics, ${ }^{2}$ Department of Chemistry, \\ Sri Ramakrishna Engineering College, 641022 Coimbatore, India \\ ${ }^{3}$ Department of Physics, Government College of Technology, 641013 Coimbatore, India \\ ${ }^{4}$ Department of Physics, Government College of Arts, 643002 Udhagamandalam, India
}

\begin{abstract}
CoMnP alloy films were synthesized by electro-deposition technique. The electro-chemical deposition technique is especially interesting due to its low cost, high throughput and high quality of deposit. Magnetic thin films are extensively used in various electronic devices including high density recording media and Micro Electro-Mechanical Systems (MEMS). Electro-deposition being cost effective in the present study cobalt based magnetic films was deposited electrochemically and deposition characteristics were studied. Effect of concentration of organic additives such as urea and thiourea in the presence of the sodium hypophosphite was studied. Structural and surface morphology was investigated by X-Ray Diffractogram (XRD) and Scanning Electron Microscope (SEM), respectively. The content of Co, Mn and P was analyzed using Energy Dispersive $\mathrm{X}$-ray Spectroscopy (EDS) technique. The hysteresis loops of the CoMnP alloy films were measured by a Vibrating Sample Magnetometer (VSM) and studies showed that organic additive has altered the magnetic properties of the films. The reas on for the change in magnetic properties and structural characteristics because of the additive were discussed. Mechanical properties such as residual stress, hardness and adhesion of the films were also examined and reported.
\end{abstract}

Key words: CoMnP thin films, organic additives, EDS, XRD, SEM, India

\section{INTRODUCTION}

Development of microelectro-mechanical systems and magnetic recording devices requires hard magnetic films with both high coercivity and remanence (Fahler et al., 2003). A promising method for the efficient and reliable fabrication of magnetically actuated MEMS is electro-deposition (Su et al., 2005). The importance of electro-deposition as fabrication technology in the electronic industry is large and growing. With the current trends towards miniaturization, cost-competitiveness and high performance packaging, electro-deposition has become the dominant manufacturing technology in many new applications and remains firmly established in others such as Micro Electro-Mechanical System (MEMS) devices, magnetic recording heads and data storage media (Myung et al., 2000; Andricacos and Bobertson, 1998; Hartmann, 1999). The electro-deposition technique is especially interesting due to its cost-effectiveness, easy maintenance and quality deposits.

As CoMnP ternary alloy films are having hard magnetic properties various studies have been carried out to develop these magnetic films (Byun et al., 1993).
Electro-deposition provides an easy way to produce these films with high quality (Emerson et al., 2004). These kinds of films were electrodeposited by Munford et al. (2002) and they studied the morphology and magnetic properties of these films. They found a convenient method for fabricating thin magnetic sensors. Numerous such applications of Co based magnetic films were reported by many researchers (Chin, 2000; Ahn and Allen, 1998).

Various cobalt based permanent magnet have been electrodeposited because of the crystalline structure of cobalt is highly anisotropic (Su et al., 2005). Electro less deposition process has been studied by a number of investigators to develop Co based magnetic thin films for magnetic recording media applications (Homma et al., 2000). However, very few electro-deposition studies have been carried out in order to study the magnetic properties of these films at various electro-deposition conditions and also with additives (Hartmann, 1999).

In the present study, we investigate in detail the effect of electro-deposition conditions and various concentrations of urea and thiourea used in the bath on the hard magnetic properties of these films by studying magnetization and demagnetization curves. In addition

Corresponding Author: M.RM. Krishnappa, Department of Physics, Sri Ramakrishna Engineering College, 641022 Coimbatore, India 
surface morphology, elemental composition, residual stress, hardness and adhesion of the coating were also studied.

\section{MATERIALS AND METHODS}

CoMnP magnetic thin films were electrodeposited from the following bath compositions as shown in Table 1. To these electrolyte organic additives like urea and thiourea were added in varying concentrations. In each concentration magnetic films were deposited to study the effect of organic additives on the mechanical and magnetic properties of $\mathrm{CoMnP}$ films.

A copper substrate of size $(2 \times 5 \mathrm{~cm})$ as cathode and pure nickel of same size as anode were used for galvanostatic electro-deposition experiments. A regulated power supply was used to pass the required current. All the chemicals used were of AR grade. An adhesive tape was used to mask off all the substrate except the area on which deposition of thin film was desired. Each substrate was polished and degreased using acetone. Just before the electro-deposition these substrates were electrocleaned in an alkaline electro-cleaning bath of sodium hydroxide: $7 \mathrm{~g} \mathrm{~L}^{-1}$; sodium carbonate: $20 \mathrm{~g} \mathrm{~L}^{-1}$; trisodium phosphate: $9 \mathrm{~g} \mathrm{~L}^{-1}$ and sodium metasilicate: $24 \mathrm{~g} \mathrm{~L}^{-1}$. The bath was operated at $70^{\circ} \mathrm{C}$ and $3 \mathrm{~A} \mathrm{dm}^{-2}$ current density and then rinsed in distilled water.

Electro-deposition was carried out with varying current densities and time of deposition. The $\mathrm{pH}$ of all the electrodeposited baths used in this research was found to be 3 .

The thickness of the deposit was tested using digital micrometer. The magnetic properties were studied using Vibrating Sample Magnetometer (VSM). X-Ray Diffraction (XRD) and Scanning Electron Microscope (SEM) were used to study the surface morphology of these magnetic films. From XRD data crystalline size of the deposited $\mathrm{CoMnP}$ and film stress were studied. Percentage of elements such as $\mathrm{Co}, \mathrm{Mn}$ and $\mathrm{P}$ present in the deposit were analyzed using Energy Dispersive Spectrometer (EDS).

Hardness of the coating was calculated using a Vicker's hardness tester by diamond intender method. Adheson of the film was tested by bent test and by scratch test.

\begin{tabular}{ll} 
Table 1: Sample composition \\
\hline Electro-chemical baths & Plating solution composition \\
\hline Solution A & $\mathrm{CoCl}_{2}: 0.42 \mathrm{M} ; \mathrm{CoSO}_{4}: 0.053 \mathrm{M}^{\prime} \mathrm{MnCl}_{2}:$ \\
& $0.4 \mathrm{M} ; \mathrm{NH}_{4} \mathrm{Cl}: 1.8 \mathrm{M}$ and $\mathrm{NaH}_{2} \mathrm{Po}_{2}: 0.2 \mathrm{M}$ \\
Solution B & Solution $\mathrm{A}$ composition plus urea $2 \mathrm{~g} \mathrm{~L}^{-1}$ \\
Solution C & Solution A composition plus urea $4 \mathrm{~g} \mathrm{~L}^{-1}$ \\
Solution D & Solution A composition plus thiourea $2 \mathrm{~g} \mathrm{~L}^{-1}$ \\
Solution E & Solution A composition plus thiourea $4 \mathrm{~g} \mathrm{~L}^{-1}$ \\
\hline
\end{tabular}

\section{RESULTS AND DISCUSSION}

Elements present in the film were analyzed by Energy Dispersive X-ray Spectroscopy (EDS) as shown in Fig. 1. Elements present in the film were analyzed by the EDS and it confirms the presence of cobalt, manganese and phosphorous in the alloy film. All deposits which were subjected to analyze have $<2 \%$ phosphorus content. It was absorbed by Miksic that the coercivity of $\mathrm{CoMnP}$ deposits increased with increasing film thickness when $\mathrm{P}$ is $<2$ wt. (\%). Phosphorous and the coercivity values increased with increase in film thickness. XRD pattern of electrodeposited $\mathrm{CoMnP}$ thin film for various bath compositions; solution $\mathrm{A}$, solution $\mathrm{B}$, solution $\mathrm{A}$ plus urea: $2 \mathrm{~g} \mathrm{~L}^{-1}$, solution $\mathrm{C}$, solution $\mathrm{A}$ plus urea: $4 \mathrm{~g} \mathrm{~L}^{-1}$, solution $\mathrm{D}$, solution A plus thiourea: $2 \mathrm{~g} \mathrm{~L}^{-1}$, solution E, Solution A plus thiouria: $4 \mathrm{~g} \mathrm{~L}^{-1}$ for $5 \mathrm{~mA} \mathrm{~cm}^{-2}$ were presented in Fig. 2a-e.

The data obtained from the XRD pattern were compared with the standard data and were found to have hexagonal close packing (hcp) structure and exhibited 201 plane predominately. The 201 plane peak is shifted in all XRD patterns due to film residual stress. In the case of films and metals, XRD peaks will be shifted because of the stress of the material (Noyan and Cohen, 1987).

In the presence of additives few low intensity peaks were also observed for $002,301,110$ and 200 planes and this is because of the formation of intermetallic CoMnP compound during electro-deposition. Shifting of peaks to the lower angles indicates the increase in lattice constant with the additive concentration.

From the XRD pattern peak, stress in the film was calculated using the formula: Young's modulus = stress/strain. The results are shown in Table 2. CoMnP film produced from a bath with low concentration of urea has low stress and this is due to uniform crystal orientation during electro-deposition. Hence, it may be noted that low concentration of urea acts as a grain refiner

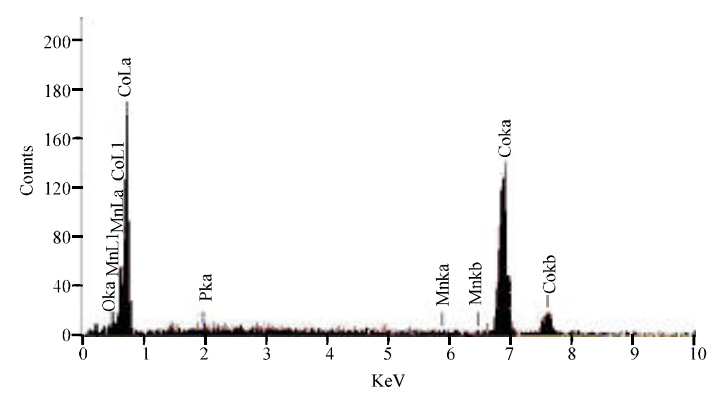

Fig. 1: EDS spectrum of electrodeposited CoMnP: time of deposition: $30 \mathrm{~min}$; current density: $5 \mathrm{mAcm}^{-2}$; $\mathrm{pH}: 3$; for solution $\mathrm{D}$ 

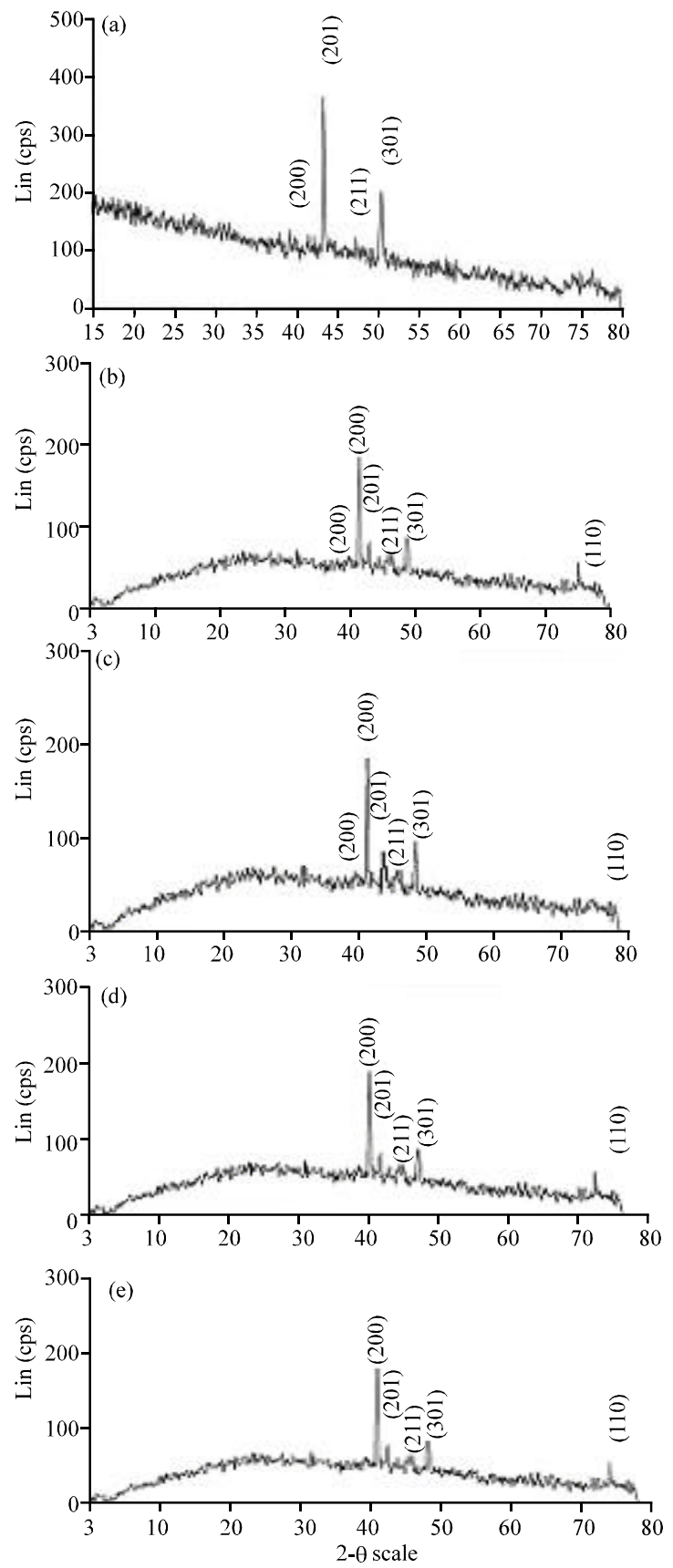

Fig. 2: XRD pattern of electrodeposited CoMnP thin film: Time of deposition $60 \mathrm{~min}$; current density: $5 \mathrm{~mA} \mathrm{~cm}{ }^{-2} ; \mathrm{pH}: 3$; a) for solution $\mathrm{A}$; b) for solution $\mathrm{B} ; \mathrm{c}$ ) for solution $\mathrm{C} ; \mathrm{d}$ ) for solution $\mathrm{D}$ and e) for solution $E$

and stress reliever. But on increasing concentration of urea and thiourea film stress is also increased. This is due to inclusion of decomposed product in the film from the additive when its concentration is higher. Crystallite size
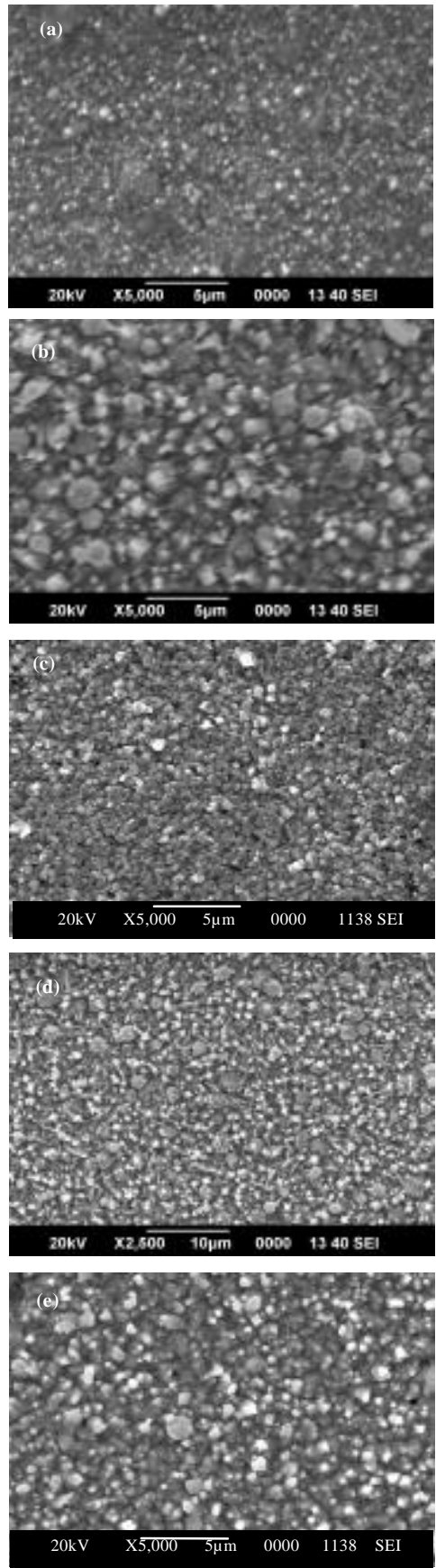

Fig. 3: SEM image of electrodeposited CoMnP film composition: Time of deposition $60 \mathrm{~min}$; current density: $5 \mathrm{~mA} \mathrm{~cm}^{-2}, \mathrm{pH}: 3$; a) for solution $\mathrm{A} ; \mathrm{b}$ ) for solution $\mathrm{B} ; \mathrm{c}$ ) for solution $\mathrm{C} ;$ d) for solution $\mathrm{D}$ and e) for solution $E$

of the deposits was calculated from the XRD pattern using the formula: crystallite size $=0.9 \lambda / \beta \cos \theta$. These values clearly show that the crystallite size of the deposite obtained by electro-deposition process is found to be 
Table 2: Magnetic properties of electrodeposited CoMnP thin films for solution A

\begin{tabular}{lcccccc}
$\begin{array}{l}\text { Current density } \\
\left(\mathrm{mA} \mathrm{cm}^{-2}\right)\end{array}$ & $\begin{array}{c}\text { Time of } \\
\text { deposition }(\mathrm{min})\end{array}$ & $\begin{array}{c}\text { Thickness of } \\
\text { deposit }(\mu \mathrm{m})\end{array}$ & $\begin{array}{c}\text { Magnetic } \\
\text { saturation }(\mathrm{emu})\end{array}$ & $\begin{array}{c}\text { Remanent } \\
(\mathrm{emu})\end{array}$ & $\begin{array}{c}\text { Coercivity } \\
(\text { Oe) }\end{array}$ & \begin{tabular}{c} 
Squareness \\
\hline 3
\end{tabular} \\
\hline 3 & 15 & 0.3 & 0.57 & 0.18 & 0.3157 \\
3 & 30 & 0.8 & 0.55 & 0.21 & 450 & 0.3818 \\
3 & 60 & 1.2 & 0.52 & 0.24 & 500 & 0.4615 \\
5 & 15 & 0.2 & 0.51 & 0.28 & 650 & 0.5490 \\
5 & 30 & 0.7 & 0.50 & 0.30 & 700 & 0.6000 \\
5 & 60 & 1.1 & 0.48 & 0.32 & 850 & 0.6666 \\
7 & 15 & 0.1 & 0.48 & 0.34 & 0.35 & 0.7083 \\
7 & 30 & 1.9 & 0.45 & 0.40 & 900 & 0.9777 \\
7 & 60 & 3.5 & 0.42 & & 0.4523 \\
\hline
\end{tabular}

Table 3: Magnetic properties of electrodeposited CoMnP thin films for Solution B-E at a constant current density $5 \mathrm{~mA} \mathrm{~cm}^{-2}$

\begin{tabular}{|c|c|c|c|c|c|c|}
\hline $\begin{array}{l}\text { Experimental } \\
\text { baths }\end{array}$ & $\begin{array}{c}\text { Time of } \\
\text { deposition (min) }\end{array}$ & $\begin{array}{l}\text { Thickness of } \\
\text { deposit }(\mu \mathrm{m})\end{array}$ & $\begin{array}{c}\text { Magnetic } \\
\text { saturation (emu) }\end{array}$ & $\begin{array}{c}\text { Remanent } \\
\text { (emu) }\end{array}$ & $\begin{array}{c}\text { Coercivity } \\
\text { (Oe) }\end{array}$ & Squareness \\
\hline Solution B & 15 & 0.6 & 0.45 & 0.06 & 800 & 0.1333 \\
\hline Solution B & 30 & 1.0 & 0.38 & 0.08 & 850 & 0.2105 \\
\hline Solution B & 60 & 1.5 & 0.34 & 0.11 & 900 & 0.3235 \\
\hline Solution $\mathrm{C}$ & 15 & 0.2 & 0.31 & 0.04 & 900 & 0.1290 \\
\hline Solution $\mathrm{C}$ & 30 & 0.8 & 0.28 & 0.05 & 1000 & 0.1785 \\
\hline Solution $\mathrm{C}$ & 60 & 1.4 & 0.26 & 0.07 & 1050 & 0.2692 \\
\hline Solution D & 15 & 0.7 & 0.40 & 0.17 & 750 & 0.4250 \\
\hline Solution D & 30 & 1.1 & 0.37 & 0.18 & 800 & 0.4864 \\
\hline Solution D & 60 & 1.4 & 0.35 & 0.20 & 900 & 0.5714 \\
\hline Solution E & 15 & 0.9 & 0.75 & 0.49 & 1100 & 0.6533 \\
\hline Solution E & 30 & 1.1 & 0.72 & 0.55 & 1150 & 0.7638 \\
\hline Solution E & 60 & 2.8 & 0.69 & 0.57 & 1250 & 0.8260 \\
\hline
\end{tabular}

Table 4: Effect of additive on the mechanical properties of CoMnP film electrodeposited at $5.0 \mathrm{~mA} \mathrm{~cm}^{-2}$ for $60 \mathrm{~min}$

\begin{tabular}{lcc}
\hline Bath composition & $\begin{array}{c}\text { Vickers Hardness } \\
\text { Number (VHN) }\end{array}$ & $\begin{array}{c}\text { Internal } \\
\text { stress (MPa) }\end{array}$ \\
\hline With out additive: solution A & 422 & 164 \\
With additive urea $2 \mathrm{~g} \mathrm{~L}^{-1}$ : solution B & 436 & 150 \\
With additive urea $4 \mathrm{~g} \mathrm{~L}^{-1}$ : solution C & 386 & 176 \\
With additive thiourea: $2 \mathrm{~g} \mathrm{~L}^{-1}$ : solution D & 446 & 178 \\
With additive thiourea: $4 \mathrm{~g} \mathrm{~L}^{-1}$ : solution E & 398 & 222 \\
\hline
\end{tabular}

in nano-scale. Electrodeposited CoMnP films from all 5 solutions (A-E) conditions as mentioned in XRD studies were subjected to SEM studies. The micrographs are presented in Fig. 3a-f. In general, micro structure of the $\mathrm{CoMnP}$ is greatly influenced by the percentage of phosphorus content. The film with very low concentration of phosphorous appeared to have a crevice pattern and it also appeared less bright to the naked eye.

The film deposited from a bath containing higher concentration of additive (urea) was cracked through the substrate probably due to the high stress associated with the film because of the additive. Stress measurement from XRD pattern also supports this result. The film deposited without organic additive was also cracked because of the phosphorus content. Electro-deposition studies were carried out using different concentrations of urea and thiourea. Urea and thiourea have been selected because they have been extensively studied as an electroplating additive in the plating perspective. Table 3 shows the magnetic properties of electrodeposited CoMnP thin films for solution A without any organic additive. Thickness of deposit increases with increase in current density and time of deposition. Films are dull in appearance and having pits. Films are having very low coercive and remanent values.

Table 4 shows the effect of current density and time of deposition on the thickness and the magnetic properties of the CoMnP films electrodeposited from a bath having solution $\mathrm{B}$ and solution $\mathrm{D}$. Thickness of the deposit increases with increase in current density. The magnetic properties of films revealed that these films are having a high coercive and low remanent value when compared to the deposits obtained from films deposited from a bath with out organic additive. Other values like magnetic saturation decrease with increase in thickness and square ness increases with increase in thickness. On increasing the concentration of urea to $4 \mathrm{~g} \mathrm{~L}^{-1}$ thickness of the deposit increased with respect to current density. Coercivity values decreased when compared to films obtained from $2 \mathrm{~g} \mathrm{~L}^{-1}$ urea containing solution. Remanent value increased at high current densities. The change in magnetic properties was because of the stress present in the magnetic film at higher concentration of urea. Effect of addditives on the thickness and magnetic properties of CoMnP films electrodeposited from a bath having solution $\mathrm{D}$ and solution $\mathrm{E}$ are presented in Table 4.

Thickness of the deposit increases with increase in current density. The magnetic properties of the films revealed that these are having a high coercive and low remanent value when compared to films produced from a bath with out organic additive on increasing the 

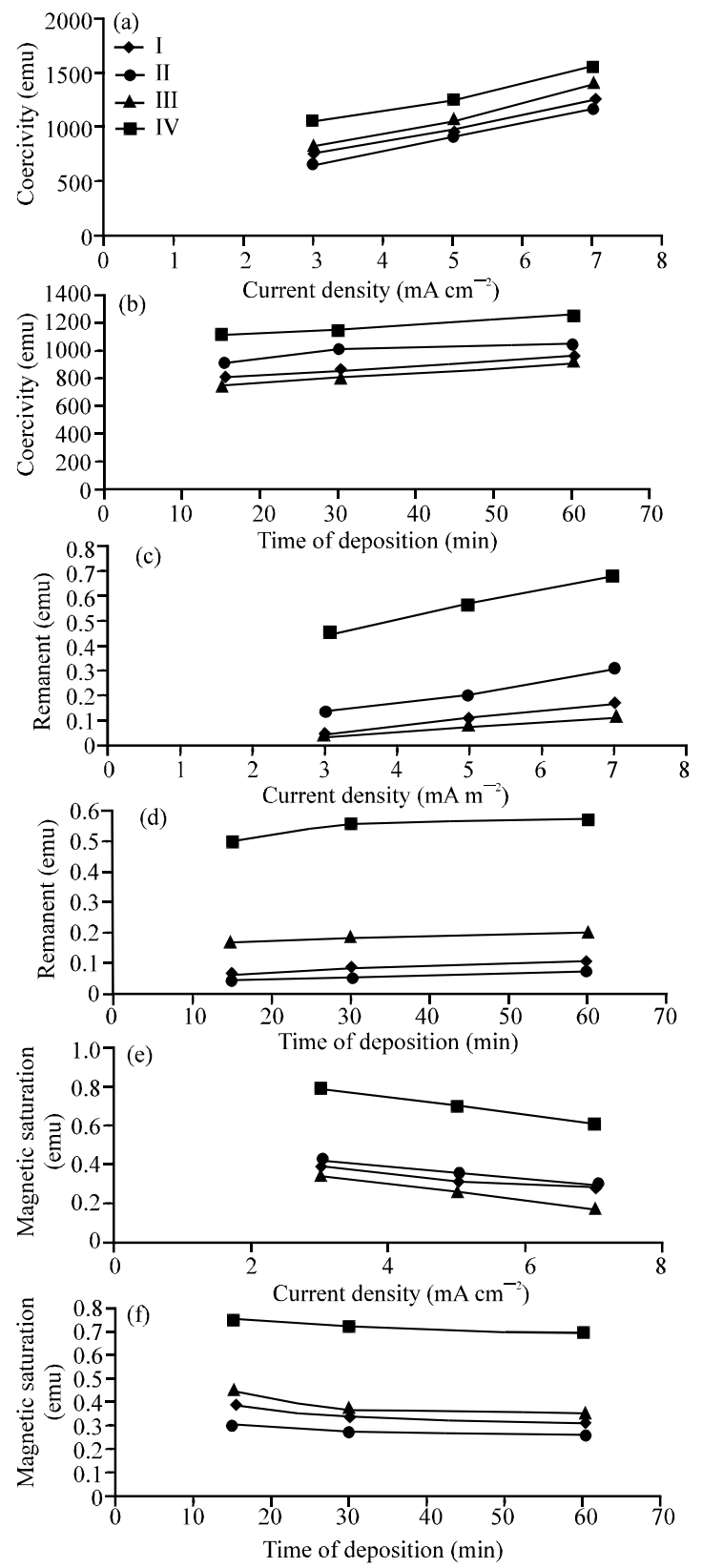

Fig. 4: Time of deposition $60 \mathrm{~min}$; $\mathrm{pH}$ : 3; a) current density verses coercivity; b): Time of deposition verses coercivity: Current density $5 \mathrm{~mA} \mathrm{~cm}{ }^{-2}$; $\mathrm{pH}: 3 ; \mathrm{c}$ ): Current density verses remanent: Time of deposition $60 \mathrm{~min}$; $\mathrm{pH}: 3$; d): Time of deposition verses remanent: Current density $5 \mathrm{~mA} \mathrm{~cm}^{-2}$; $\mathrm{pH}$ : 3 ; e): current density verses magnetic saturation: Time of deposition $60 \mathrm{~min}$; $\mathrm{pH}: 3$; f): time of deposition verses magnetic saturation [I) for solution $\mathrm{B}$; II) for solution $\mathrm{C}$; III) for solution $\mathrm{D}$ and IV) for solution $\mathrm{E}$ ] concentration of thiourea to $4 \mathrm{~g} \mathrm{~L}^{-1}$, thickness of the deposit increased with respect to current density. Coercivity value decreased. Figure 4a shows the effect of current density on coercivity for all baths under study with additive for electro-deposition. Figure 4 clearly shows that the coercivity values increase with increase in current density for all four types of baths under study. It also clearly reveals that increase in the concentration of urea decreases coercivity.

The same type of results was noted from Fig. 4b which is a plot between the time of deposition and coercivity. Figure $4 c$, d shows the effect of current density and time of deposition on the remanent values of the deposits. Like coercive values these values are not in an order, i.e., it also increases with increase in curtrent density and time of deposition but on increasing the concentration of urea, remanent values increases. Magnetic saturation of these films decrease with increase in current density and time of deposition this is shown in Fig. $3 f$ and $4 \mathrm{e}$.

As the average crystallite size of these films is in the nano scale, considerable changes in the magnetic behaviour can occur. When the crystallize size is reduced to the extend that the domine wall thickness is comparable to the crystallite size the coercivity is found to decrease. But the coercivity increases when crystallite approaches high nano level. This is mainly due to the phosphorous content in the deposit which was produced from a bath having thiourea $4 \mathrm{~g} \mathrm{~L}^{-1}$ concentrations. Analysis of crystallite size, microstructure and magnetic properties confirms that the origins of magnetic properties are because of the strongly interacting array of single domain crystals. This is mainly due to the presence of phosphorous which was incorporated in to the CoMnP films at the required level of the additive. Adheson of the film was tested by bent test (bending the film with the substrate is $180^{\circ}$ ) and by scratch test (draw equal lines by pin and paste an adhesive tape over the scratches and pull it. If the film comes with the tape then the adhesion is poor). It is showed that the film is having a good adhesion with the substrate.

Hardness of these films was examined using a Vicker's hardness tester by the diamond intender method. Table 1 gives the hardness values. Hardness of the film decreases when concentration of urea increases. This may also be due to the higher stress associated with CoMnP film when it is electrodeposited from a bath containing higher concentration of organic addititive. Relative high hardness values for these CoMnP thin film alloys deposited is due to the fact that nano-crystalline alloys offer significantly increased strength. 


\section{CONCLUSION}

CoMnP film having good hard magnetic properties can be prepared. Under best condition involving addition of $0.2 \mathrm{M}$ of $\mathrm{NaH}_{2} \mathrm{PO}_{2}$ and $4 \mathrm{~g} \mathrm{~L}^{-1}$ of thiourea at current density $5 \mathrm{~mA} \mathrm{~cm}^{-2}$ and time of deposition $60 \mathrm{~min}$, the thickness of the film was found to be 2.8 micrometer with coercivity $1250 \mathrm{Oe}$. Further increase in the concentration of thiourea and urea will decrease the hard magnetic properties. It also increases the film stress which is a cause for cracked film. As these types of magnetic films are used in MEMS devices, they should have minimum stress. Hardness of the films is decreased because of the additive concentration. But organic additive like thiourea in low concentration will produce a good CoMnP film which can be used in MEMS devices because these film have high coercive and low remanent values. Also these films have low stress, good adhesion with the substrate and their crystallite sizes are in nano-scale.

\section{ACKNOWLEDGEMENTS}

The researchers thank the management of Sri Ramakrishna Engineering College for their support and kind permission to publish this research.

\section{REFERENCES}

Ahn, C.H. and M.G. Allen, 1998. Micromachined planar inductors on silicon wafers for MEMS applications. IEEE Trans. Ind. Electr., 45: 866-876.

Andricacos, P.C. and N. Bobertson, 1998. Future directions in electroplated materials for thin-film recording heads. IBM J. Res. Dev., 42: 671-680.

Byun, C., G.C. Rauch, D.J. Young, C.A. Klepper and Jr. Greggi, 1993. Effects of hypophosphite contents and surface treatment on electroplated Co-Ni-P thin films. J. Appl. Phys., 73: 5575-5577.
Chin, T.S., 2000. Permanent magnet films for microelectro-mechnaical system applications. J. Magm. Magn. Mater., 209: 75-79.

Emerson, R.N., C.J. Kennady and S. Ganesan, 2004. Electrodeposition of CoNiP magnetic thin films from ammonium chloride based electrolyte. J. Electrochem. Soc. Ind., 54: 74-77.

Fahler, S., U. Hannemann, S. Oswald, V. Neu, B. Holzapfel and L. Schultz, 2003. Corrosion of highly coercive, highly textured Nd-Fe-B films. IEEE Trans. Mag., 39: $2950-2952$.

Hartmann, U., 1999. Magnetic Multilayers and Giant Magnetoresistance: Fundamentals and Industrial Applications. Springer Series in Surface Sciences. Vol. 37, Springer, Berlin.

Homma, T., Y. Kita and T. Osaka, 2000. Microstructural study on the functionally graded magnetic thin films prepared by electroless deposition. J. Electrochem. Soc., 147: 160-163.

Munford, M.L., M.L. Sartorelli, L. Seligman and A.A. Pasa, 2002. Morphology and magnetic properties of Co thin films e lectrodeposited on Si. J. Electrochem. Soc., 149: 274-279.

Myung, N.V., D. Y. Park, M. Schwartz, K. Nobe, H. Yang, C.K. Yang and J.W. Judy, 2000. Electrodeposited hard magnetic thin films for mems electrodeposited hard magnetic thin films for mems applications. Proceedings of the 6th International Symposium on Magnetic Materials Processes and Devices, Proc. Electrochem Sor, PV 2000-2029(2000). http://www.ee. ucla.edu/ jjudy/publications/conference/ecs_2000 _myung_et_al.pdf.

Noyan, I.C. and J.B. Cohen, 1987. Residual Stress: Measurement by Diffraction and Interpretation. 1st Edn., Springer-Verlag, Berlin, pp: 276.

Su, Y., H. Wang, G. Ding, F. Cui, W. Zhang and W. Chen, 2005. Electroplated hard magnetic material and its application in microelectromechanical systems. IEEE Trans. Mag., 41: 4380-4383. 